Chem. Phys. Lett. in press

\title{
Synthesis of single-walled carbon nanotubes with narrow diameter-distribution from fullerene
}

\author{
Shigeo Maruyama*, Yuhei Miyauchi, Tadao Edamura, Yasuhiro Igarashi, \\ Shohei Chiashi, Yoichi Murakami \\ Department of Mechanical Engineering, The University of Tokyo \\ 7-3-1 Hongo, Bunkyo-ku, Tokyo 113-8656, Japan \\ Received 15 April 2003; in final form 25 April 2003
}

\begin{abstract}
Single-walled carbon nanotubes with narrow diameter-distributions were synthesized by the catalytic CVD technique using fullerene, $\mathrm{C}_{60}$ or $\mathrm{C}_{70}$, as the carbon source. $\mathrm{Fe} / \mathrm{Co}$ bimetal particles supported with zeolite powder were exposed to fullerene vapor in a heated quartz tube furnace. With a precise control of fullerene vapor pressure, macroscopic amounts of SWNTs with relatively high quality were generated. The diameter distributions of SWNTs, estimated by an analysis of resonance Raman scattering using excitation wavelengths of 633, 514.5 and $488 \mathrm{~nm}$, ranged between 0.8 to $1.1 \mathrm{~nm}$. The narrowness of this distribution is ascribed to the formation of nanotube caps due to fullerene collisions.
\end{abstract}

*Corresponding Author. Fax: +81-3-5800-6983.

E-mail address: maruyama@photon.t.u-tokyo.ac.jp (S. Maruyama). 


\section{Introduction}

The unique properties of single-walled carbon nanotubes (SWNTs) [1] strongly depend on their geometrical structure, such as the chirality-dependent metallic/semiconducting duality or the variable band gaps inversely proportional to their diameters [2]. In addition to the early laser-furnace [3] and arc-discharge [4] techniques, various kinds of catalytic CVD (CCVD) techniques [5-7] have been developed for the large-scale production of SWNTs with high purity. However, chirality-controlled synthesis of SWNTs has not been possible in any of these techniques. Furthermore, the diameter distribution achieved by the seemingly promising CCVD techniques is in general broader than the earlier laser-furnace techniques. In this report, fullerene has been used as the carbon source in the CCVD synthesis in order to investigate the possibility of controlling aforementioned SWNT geometries.

Several attempts have so far been made to synthesize carbon nanotubes using fullerene [8-13]. Zhang and Iijima [8] used $\mathrm{C}_{60}$ powder with 5 at.\% $(\mathrm{Ni}+\mathrm{Co})$ as the target material of the laser-furnace technique and produced a small amount of SWNT at $400{ }^{\circ} \mathrm{C}$, which is much lower than the lower threshold, about $850{ }^{\circ} \mathrm{C}$, of the usual graphite/metal target. Champbell et al. $[9,10]$ tried to produce nanotubes by the CCVD method, but their products were multi-walled carbon nanotubes (MWNTs). In one of the studies where multi-layered fullerene/catalyst films were used as a source of carbon nanotubes [11-13], the samples once claimed to be single crystal SWNTs synthesized from $\mathrm{C}_{60}$ and Ni layers [13] turned out to be those of Mo oxide. Apparently, no group has yet demonstrated to synthesize a macroscopic amount of SWNTs from fullerene except for that by the laser-furnace technique [8] and the reports where carbon nanotubes were used as templates: i.e., high-temperature transformation of peapods to double-walled carbon nanotubes (DWNTs) [14]. Formation models of SWNTs in the laser-furnace and arc-discharge techniques have so far 
been studied extensively [3, 15-17]. Formation of nanoscale metal particles is generally accepted as the key issue for the growth of SWNTs $[15,16]$, especially as a common source of strategy for the CCVD generation of SWNTs [5]. In discussions of the formation mechanism, a unique model that has been used [17] assumes a fullerene cap structure as an important precursor of SWNT determining its diameter. In addition, molecular dynamics simulations on the process of nanotube formation [18, 19] and an FT-ICR study of clusters generated by laser vaporization [20] partially support the fullerene precursor model. Being stimulated by these models, we have been trying for several years to use fullerene as a carbon source for the CCVD synthesis of SWNTs. Here we report formation of relatively high-quality SWNTs by a simple CCVD experiment with a suitable catalyst and by a precise control of fullerene vapor pressure. The diameter distribution is found to be narrower than any of those prepared by other CCVD experiments.

\section{Experimental}

The experimental techniques were similar to our catalytic CVD method using alcohol [7, 21]. The metal catalyst supported with zeolite was prepared according to the recipe of Shinohara's group [22, 23]. In brief, iron acetate $\left(\mathrm{CH}_{3} \mathrm{CO}_{2}\right)_{2} \mathrm{Fe}$ and cobalt acetate $\left(\mathrm{CH}_{3} \mathrm{CO}_{2}\right)_{2} \mathrm{Co}-4 \mathrm{H}_{2} \mathrm{O}$ were dissolved in ethanol (typically $40 \mathrm{ml}$ ) and mixed with Y-type zeolite powder [HSZ-390HUA] (typically $1 \mathrm{~g}$ ). The amounts of $\mathrm{Fe}$ and Co were $2.5 \mathrm{wt} \%$ each. The solution was then sonicated for $10 \mathrm{~min}$ and dried for $24 \mathrm{~h}$ at $80{ }^{\circ} \mathrm{C}$. The resultant white-yellow powder was dispersed in ethanol again and uniformly coated on the inner surface of a half-cut cylinder-shaped quartz boat. The schematics of CVD apparatus are shown in Fig. 1(a). The catalyst-coated quartz boat was placed in a quartz tube (i. d. $26 \mathrm{~mm}$ ) at the downstream side from the center of Furnace B. The fullerene power (typically $100 \mathrm{mg}, 99.5 \% \mathrm{C}_{60}$ or $\mathrm{C}_{70}$ supplied from SES Research) was placed in small

quartz test-tube (i. d. $4.5 \mathrm{~mm}$ ) one end closed and the other sealed with quartz wool. A 
thermocouple attached to this test-tube with an inorganic adhesive was essential for reproducible experiments. The test-tube was placed in Furnace A, so that fullerene powder should stay at the center of this furnace. During the heating up, Furnace A was located at the upstream side away from fullerene powder and Ar gas of more than $200 \mathrm{sccm}$ was kept flowing. After Furnace B reached the desired temperature, $825{ }^{\circ} \mathrm{C}$, Ar remaining inside the quartz tube was evacuated and the powder of fullerene was quickly heated up by sliding back the heated Furnace A to the position in Fig. 1(a). The background pressure was about 0.05 Torr. By evacuation of inside the quartz tube with a rotary pump, vaporized fullerene was supplied over the catalyst for $10 \mathrm{~min}$.

For a successful synthesis of SWNTs, the history of temperature increase in the test tube containing fullerene was crucial. The temperature change measured with a thermocouple (TC) at the fullerene test-tube is shown in Fig. 1(b) along with the estimated $\mathrm{C}_{60}$ vapor pressure. After sliding back the heated Furnace A set at $750{ }^{\circ} \mathrm{C}$, it took about 5 min before the temperature of the test-tube containing fullerene reached about $700{ }^{\circ} \mathrm{C}$ according to the TC indication. For an average of experimental correlations summarized in Ref. [24], we used the following correlation to estimate the vapor pressure of $\mathrm{C}_{60}$ plotted in Fig. 1(b).

$$
p / \text { Torr }=7.5 \times 10^{8} \times 10^{-9500 /(T / K)}
$$

During the heating up of fullerene powder, the vapor pressure, and hence the flow rate, of fullerene vapor suddenly increased after about $5 \mathrm{~min}$. Since no fullerene powder was left in the test tube after 10 min experiments, evaporation of fullerene was achieved in a relatively short period. The upper limit of fullerene temperature was set so that essentially no decomposed fullerene was left in the test tube and most of the sublimed fullerene film downstream of Furnace B was dissolvable in toluene.

After cooling down, the sample was analyzed by resonance Raman spectroscopy and transmission electron microscopy (TEM). Raman scattering was measured with Chromex 501 is and Andor Technology DV401-FI for the spectrometer and CCD system, respectively, with an optical 
system of Seki Technotron STR250. TEM was measured by JEM2000FX at $200 \mathrm{kV}$.

\section{Results and discussion}

Figure 2 shows TEM images of 'as grown' SWNTs synthesized from $\mathrm{C}_{60}$. In order to remove $\mathrm{C}_{60}$ physically absorbed on the outside of carbon nanotubes, the sample was first washed and sonicated in toluene for $10 \mathrm{~min}$ at room temperature. Then, the sample was sonicated in methanol and a drop was evaporated on the micro-grid for TEM. As displayed in Fig. 2(a), zeolite particles (on left) and bundles of SWNTs were observed. Clean bundles of SWNTs were observed. From the upstanding view of a bundle in Fig. 2(b), the diameter of SWNTs is estimated to be about $1 \mathrm{~nm}$. The SWNT diameter is thinner and the diameter distribution is considerably narrower than the corresponding values of the SWNTs samples from ethanol. As in Fig. 2(a) some large metal particles (dark dots) are observed near zeolite particles and sometimes inside of a bundle of SWNTs. The amount of SWNTs is much less than the sample from alcohol CCVD [7, 21], and a small amount of imperfect MWNTs are also observed in certain TEM observation spots, probably because of the non-uniformity of catalysts. We could not observe peapods or DWNTs, probably because the diameters of synthesized SWNTs were too small. In contrast, we could observe thicker SWNTs, peapods, and DWNTs in our preliminary experiments at higher CCVD temperature such as $900{ }^{\circ} \mathrm{C}$.

Figure 3 shows Raman scattering spectra from an 'as-grown' sample synthesized from $\mathrm{C}_{60}$ and $\mathrm{C}_{70}$ in comparison with the CCVD samples generated from 5 Torr ethanol at 700 and $800{ }^{\circ} \mathrm{C}[7$, 21]. The excitation wavelength was $633 \mathrm{~nm}$ with He-Ne laser. The clear radial breathing modes (RBM) (150-300 $\mathrm{cm}^{-1}$ ) and the G-band with the zone-folding spread (about $1590 \mathrm{~cm}^{-1}$ ) were observed for both samples from $\mathrm{C}_{60}$ and $\mathrm{C}_{70}$. The D-band signal (about $1350 \mathrm{~cm}^{-1}$ ) for the samples synthesized from fullerene was nearly identical with that obtained by alcohol CCVD. From the expanded RBM signal in panel A, the diameter of SWNTs is estimated to be typically $0.8-1.1 \mathrm{~nm}$. 
Here, the following correlation $[25,26]$ between the diameter $d$ and the RBM Raman shift $v$ was used for the upper coordinate in panel A: $d / \mathrm{nm}=248 /\left(\mathrm{v} / \mathrm{cm}^{-1}\right)$. Note that a considerable background is present in the Raman spectra of the samples from fullerene because the amount of SWNTs was quite small. The diameter distribution of the samples from fullerene was much narrower than those from ethanol. Note also that the samples from fullerene had only a small amount of metallic resonant peaks, BWF line shapes $[27,28]$ observed near the G-band in panel B for the cases of ethanol.

Detailed comparisons of the RBM Raman shift with the Kataura plot [28] in the form reported in Ref. [25] are shown in Fig. 4. Here, the sample from $\mathrm{C}_{70}$ and that from ethanol at $800{ }^{\circ} \mathrm{C}$ are compared at $633,514.5$, and $488 \mathrm{~nm}$. The peak positions of the samples from $\mathrm{C}_{70}$ are identical with those from ethanol, and only the relative peak intensities are different. The change in the resonant condition with 514.5 and $488 \mathrm{~nm}$ excitation can be understood from the Kataura plot. However, the resonant condition in this plot is apparently violated in the $633 \mathrm{~nm}$ measurements of the alcohol CCVD case, as denoted by asterisks in Fig. 4(f). A probable reason is the resonance condition of the $i$ th valence van Hove singularity level to the $i \pm 1$ th level because the resonance occurs with the light polarized perpendicular to the nanotube axis $[29,30]$. Nearly the same violation at $633 \mathrm{~nm}$ was observed for the HiPco sample [6] (not shown). It seems, however, that samples from fullerene do not violate this resonant condition, probably because the bundles were thinner and straighter [29]. It is recognized by a comparison of three laser wavelengths that the small peak around $190 \mathrm{~cm}^{-1}$ in Fig. 4(c) is due to the very close resonance at $633 \mathrm{~nm}$. Hence, the diameter distribution of SWNTs generated from fullerene is estimated to be between 0.8 to $1.1 \mathrm{~nm}$.

Zhang and Iijima [8] estimated the diameter distribution of SWNTs generated from fullerene by the laser-furnace method by TEM as $1.2-1.3 \mathrm{~nm}$; this is slightly smaller than the normal graphite case. They argued that $\mathrm{C}_{60}$ was a good starting material for the laser-furnace generation of 
SWNTs at low temperature because the initial types and energies of carbon species ablated from $\mathrm{C}_{60}$ were different. Unlike the laser ablation method, we do not expect much decomposition of fullerene in our CCVD method before the collision to the metal catalyst. Most of the fullerene material escaped from the CCVD furnace should keep fullerene structure. Formation of the SWNTs obtained with smaller diameters and with a higher yield by the present CCVD method needs to be explained by a mechanism different from that discussed in Ref. [8].

The diameter distribution of SWNTs from fullerene could be interpreted using the preliminary molecular dynamics simulation shown in Fig. 5. This simulation is based on the classical potential functions described in Refs. $[18,19]$ but uses a different initial condition: $\mathrm{C}_{60}$ molecules are collided onto a pre-formed metal cluster surface. The discussion from the results of simulation has to be only semi-quantitative, because simulation temperature as high as $2500 \mathrm{~K}$ is employed for the acceleration of the annealing process and the choice of the collision rate of $\mathrm{C}_{60}$ is arbitrary. Nevertheless, this simulation is useful to explore what would happen in the real CCVD process. When the metal-carbon binary cluster is saturated after absorption of many $\mathrm{C}_{60}$ molecules, several nano-cap structures are generated by additional collisions of $\mathrm{C}_{60}$. One may assume that the diameters of SWNT are equal to that of fullerene, say $0.7 \mathrm{~nm}$ for $\mathrm{C}_{60}$, if the hemispherical cap structure of fullerene is directly used as the cap structure. The 'Cap A' structure in Fig. 5 is a demonstration of this case. In cases of 'Cap B' and 'Cap C' in Fig. 5, however, the fullerene precursor can easily modify its bonding network on the metal cluster surface under the condition that SWNTs can be grown from a metal-carbon binary cluster. The accommodation of this cap structure to a rather complicated metal-carbon binary cluster is also important for the final settlement of the cap structure and for the expected growth of SWNT from this cap structure. The number of carbon atoms used for the cap structure strongly depends on the dynamics of these bond-network modifications. Under the assumption that the number of atoms used for cap 
formation varies from 30 to 60 , the diameters of the SWNTs are estimated to be between 0.7 to 1.2 $\mathrm{nm}$, in good agreement with the present experimental results. Here we believe that the nucleation of cap structures is somehow controllable by a proper adjustment of the structure of the carbon source molecule as well as the structures of the nanoscale metal particle.

\section{Acknowledgement}

The authors thank Mr. H. Tsunakawa (The University of Tokyo) for assistance in TEM measurements. Part of this work was supported by KAKENHI \#12450082 and 13555050 from JSPS, and \#13GS0019 from MEXT.

\section{References}

[1] S. Iijima, T. Ichihara, Nature 363 (1993) 603.

[2] R. Saito, G. Dresselhaus, M.S. Dresselhaus, Physical Properties of Carbon Nanotubes, Imperial College Press, London, 1998.

[3] A. Thess, R. Lee, P. Nikolaev, H. Dai, P. Petit, J. Robert, C. Xu, Y.H. Lee, S.G. Kim, A.G. Rinzler, D.T. Colbert, G.E. Scuseria, D. Tománek, J.E. Fischer, R.E. Smalley, Science 273 (1996) 483.

[4] C. Journet, W.K. Maser, P. Bernier, A. Loiseau, M.L. de la Chapelle, S. Lefrant, P. Deniard, R. Lee, J.E. Fisher, Nature 388 (1997) 756.

[5] H. Dai, A.G. Rinzler, P. Nikolaev, A. Thess, D.T. Colbert, R.E. Smalley, Chem. Phys. Lett. $260(1996) 471$.

[6] P. Nikolaev, M.J. Bronikowski, R.K. Bradley, F. Rohmund, D.T. Colbert, K.A. Smith, R.E. Smalley, Chem. Phys. Lett. 313 (1999) 91. 
[7] S. Maruyama, R. Kojima, Y. Miyauchi, S. Chiashi, M. Kohno, Chem. Phys. Lett. 360 (2002) 229.

[8] Y. Zhang, S. Iijima, Appl. Phys. Lett. 75 (1999) 3087.

[9] L.P. Biró, R. Ehlich, R. Tellgmann, A. Gromov, N. Krawez, M. Tschaplyguine, M.-M. Pohl, E. Zsoldos, Z. Vértesy, Z.E. Horváth, and E.E.B. Champbell, Chem. Phys. Lett. 306 (1999) 155.

[10] O.A. Nerushev, S. Dittmar, R.-E. Morjan, F. Rohmund, E.E.B. Campbell, J. Appl. Phys. 93 (2003) 4145.

[11] E. Czerwosz, P. Dłużewski, G. Dmowska, R. Nowakowski, E. Starnawska, H. Wronka, Appl. Surf. Sci. 141 (1999) 350.

[12] E. Czerwosz, P. Dłużewski, Diamond Related Mater. 9 (2000) 901.

[13] R.R. Schlittler, J.W. Seo, J.K. Gimzewski, C. Durkan, M.S.M. Saifullah, M.E. Welland, Science 292 (2001) 1136.

[14] B.W. Smith, M. Monthioux, D.E. Luzzi, Chem. Phys. Lett. 315 (1999) 31.

[15] M. Yudasaka, R. Yamada, N. Sensui, T. Wilkins, T. Ichihashi, S. Iijima, J. Phys. Chem. B 103 (1999) 6224.

[16] M. Yudasaka, Y. Kasuya, F. Kokai, K. Takahashi, M. Takizawa, S. Bandow, S. Iijima, Appl. Phys. A 74 (2002) 377.

[17] H. Kataura, Y. Kumazawa, Y. Maniwa, Y. Ohtsuka, R. Sen, S. Suzuki, Y. Achiba, Carbon 38 (2000) 1691.

[18] Y. Shibuta, S. Maruyama, Physica B 323 (2002) 187.

[19] S. Maruyama, Y. Shibuta, Mol. Cryst. Liq. Cryst. 387 (2002) 87.

[20] M. Kohno, S. Inoue, R. Kojima, S. Chiashi, S. Maruyama, Physica B 323 (2002) 272.

[21] Y. Murakami, Y. Miyauchi, S. Chiashi, S. Maruyama, Chem. Phys. Lett. in press.

[22] K. Mukhopadhyay, A. Koshio, N. Tanaka, H. Shinohara, Jpn. J. Appl. Phys. 37 (1998) L1257. 
[23] K. Mukhopadhyay, A. Koshio, T. Sugai, N. Tanaka, H. Shinohara, Z. Konya, J. B. Nagy, Chem. Phys. Lett. 303 (1999) 117.

[24] R. Pankajavalli, C. Mallika, O.M. Sreedharan, M. Premila, P. Gopalan, Thermochemica Acta $16(1998) 101$.

[25] R. Saito, G. Dresselhaus, M.S. Dresselhaus, Phys. Rev. B 61 (2000) 2981.

[26] A. Jorio, R. Saito, J.H. Hafner, C.M. Lieber, M. Hunter, T. McClure, G. Dresselhaus, M.S. Dresselhaus, Phys. Rev. Lett. 86 (2001) 1118.

[27] A.M. Rao, E. Richter, S. Bandow, B. Chase, P.C. Eklund, K.A. Williams, S. Fang, K.R. Subbaswamy, M. Menon, A. Thess, R.E. Smalley, G. Dresselhaus, M.S. Dresselhaus, Science 275 (1997) 187.

[28] H. Kataura, Y. Kumazawa, Y. Maniwa, I. Umezu, S. Suzuki, Y. Ohtsuka, Y. Achiba, Synth. Met. 103 (1999) 2555.

[29] R. Saito, A. Grueneis, T. Kimura, A. Jorio, A.G.S. Filho, G. Dresselhaus, M.S. Dresselhaus, M.A. Pimenta, 58th Annual Meeting JPS 58 (2003) 825.

[30] A. Grüneis, R. Saito, Ge.G. Samsonidze, T. Kimura, M.A. Pimenta, A. Jorio, A.G.S. Filho, G. Dresselhaus, M.S. Dresselhaus, Phys. Rev. B 67 (2003) 165402. 


\section{Figure Captions}

Fig. 1. Experimental apparatus and evaporation conditions of fullerene. (a) Schematics of experimental apparatus. (b) Temperature change in the test-tube with fullerene and estimated vapor pressure of $\mathrm{C}_{60}$.

Fig. 2. TEM ( $200 \mathrm{kV})$ image of 'as grown' SWNTs by catalytic decomposition of $\mathrm{C}_{60}$ over a Fe/Co mixture embedded in zeolite at $825{ }^{\circ} \mathrm{C}$. (a) Low-magnification image: zeolite particles are observed in left-hand side. (b) Higher magnification image of an upstanding bundle.

Fig. 3. Resonant Raman scattering spectra of 'as-grown' SWNTs synthesized from fullerene and ethanol (excitation at $633 \mathrm{~nm}$ ). Panel A is an expanded view of low-frequency range of panel B: from (a) $\mathrm{C}_{60}$, (b) $\mathrm{C}_{70}$, (c) ethanol at $700{ }^{\circ} \mathrm{C}$, and (d) ethanol at $800{ }^{\circ} \mathrm{C}$.

Fig. 4. Radial breathing mode of SWNTs from fullerene and ethanol compared with the Kataura plot $\left(a_{\mathrm{cc}}=0.144 \mathrm{~nm}, \gamma_{0}=2.9 \mathrm{eV}\right)$. Asterisks denote the RBM peaks apparently violating the selection rule expressed by the Kataura plot.

Fig. 5. A snapshot of molecular dynamics simulation of nanotube cap formation process from $\mathrm{C}_{60}$. Simulation of successive collisions of $\mathrm{C}_{60}$ molecules to a $\mathrm{Ni}_{256}$ cluster at an interval of 2 ns at $2500 \mathrm{~K}$. Gray circles and line-segments represent metal atoms and carbon bonds, respectively. 


\section{Fe/Co embedded}

in zeolite powder

on half-cut of quartz tube

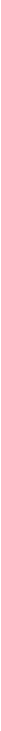

Fig. 1(a) 


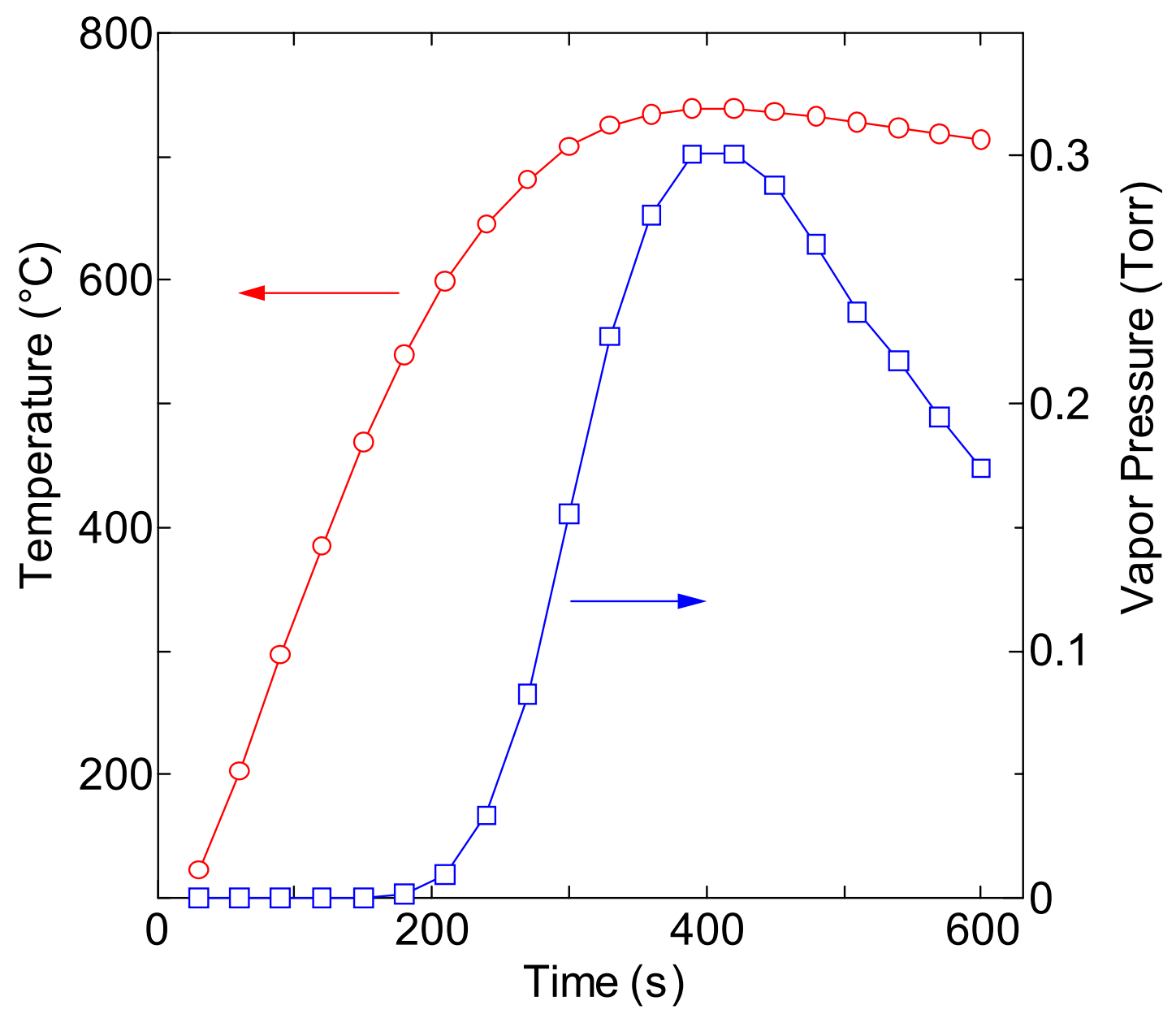

Fig. 1(b) 


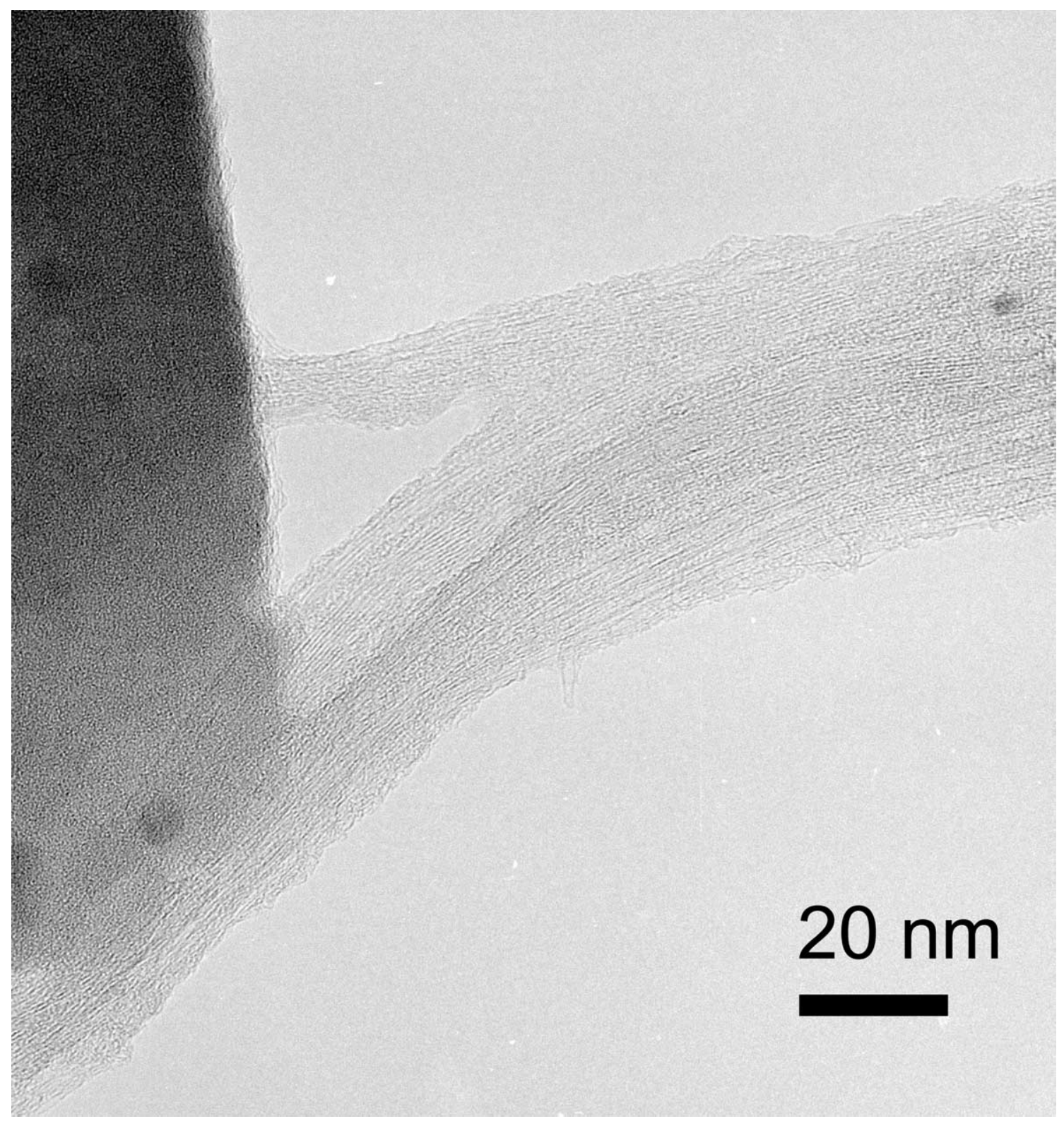

Fig. 2(a) 


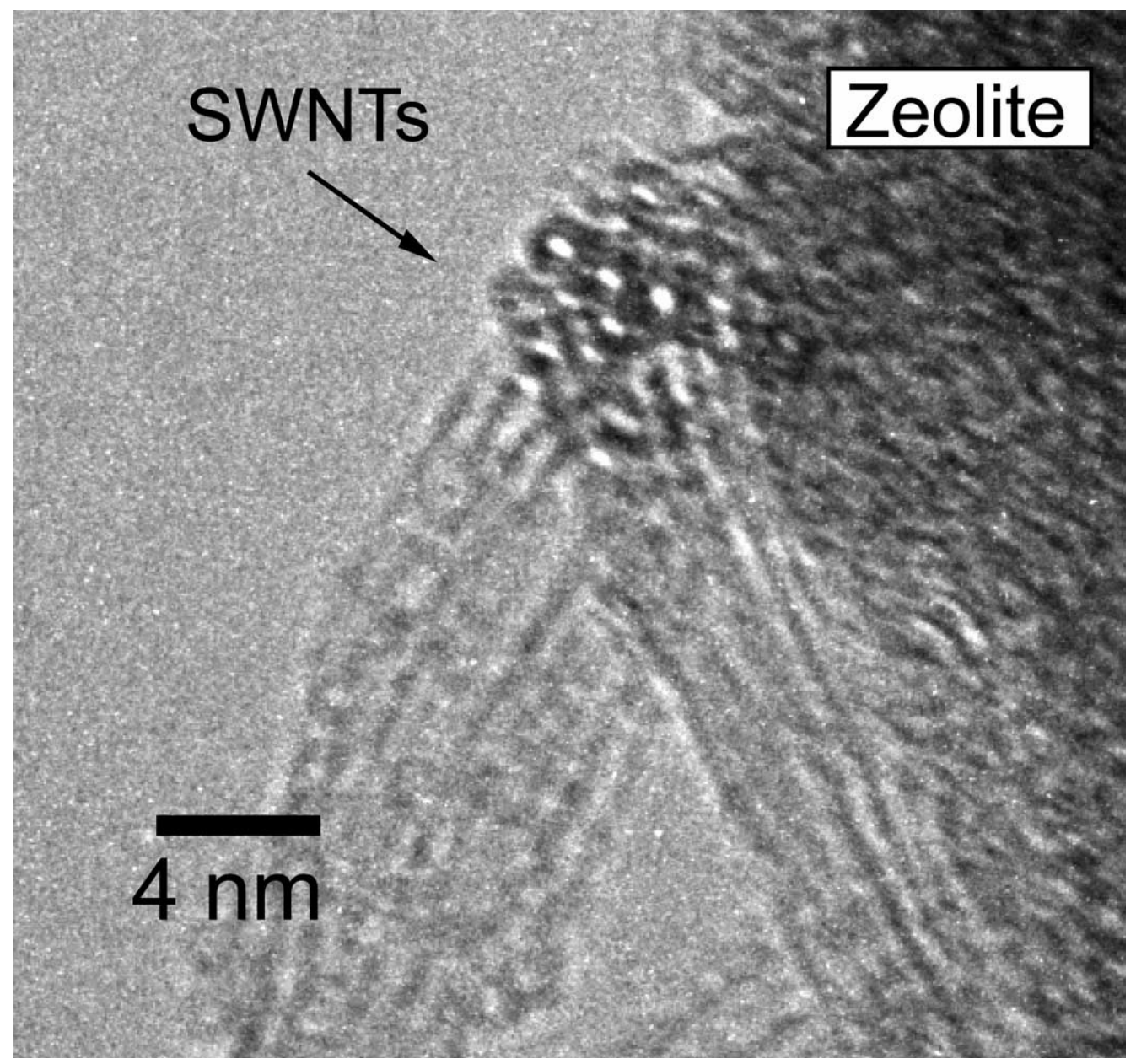

Fig. 2(b) 

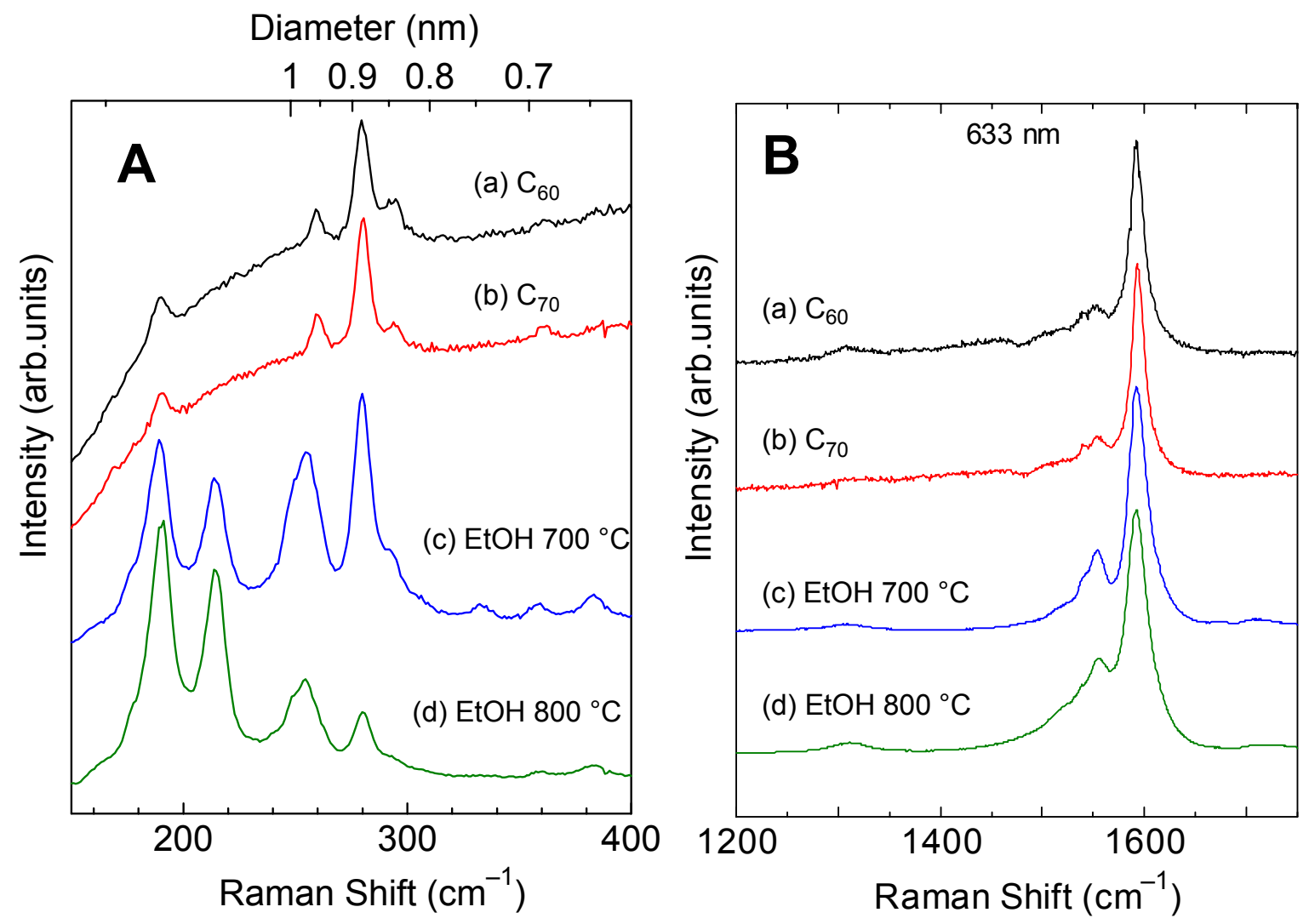

Fig. 3 


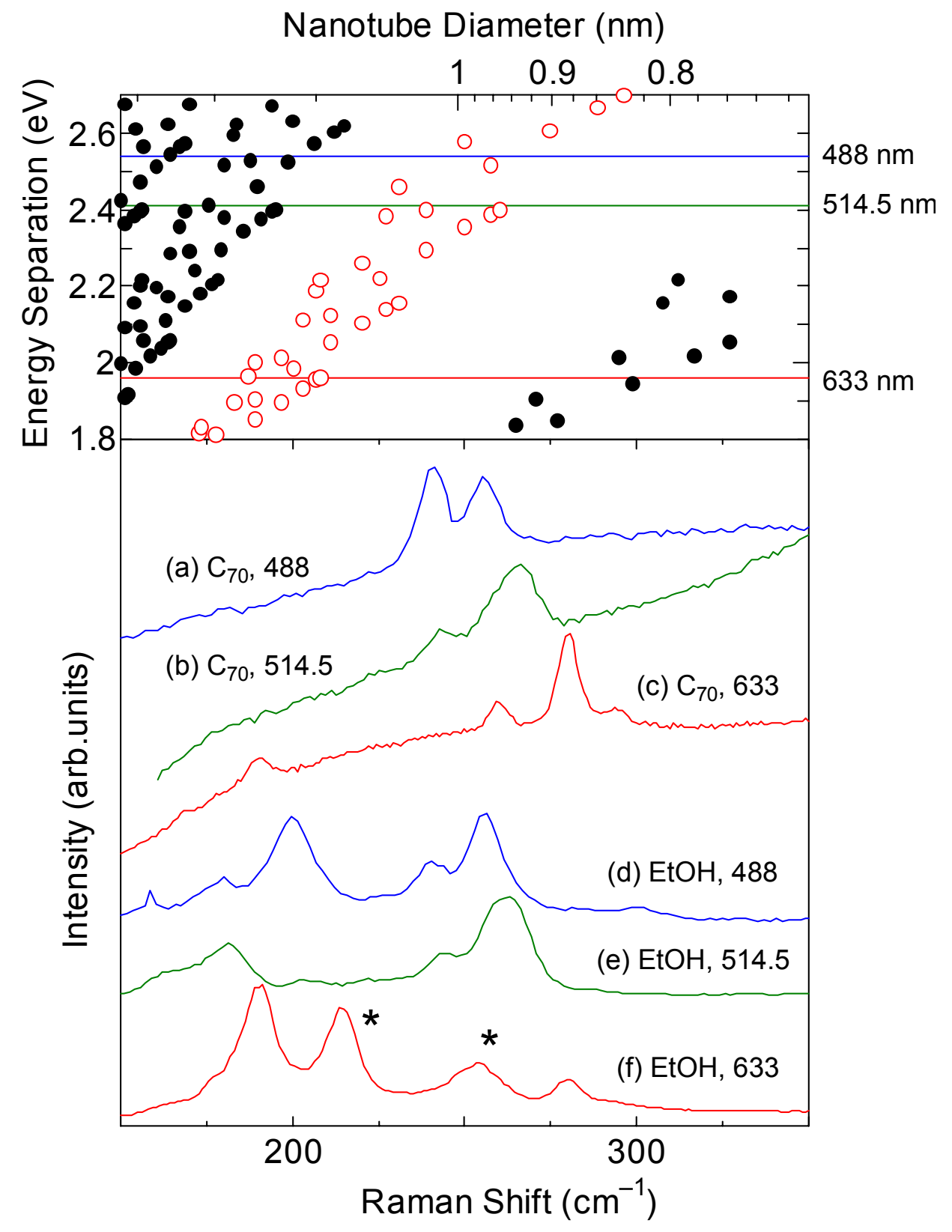

Fig. 4 


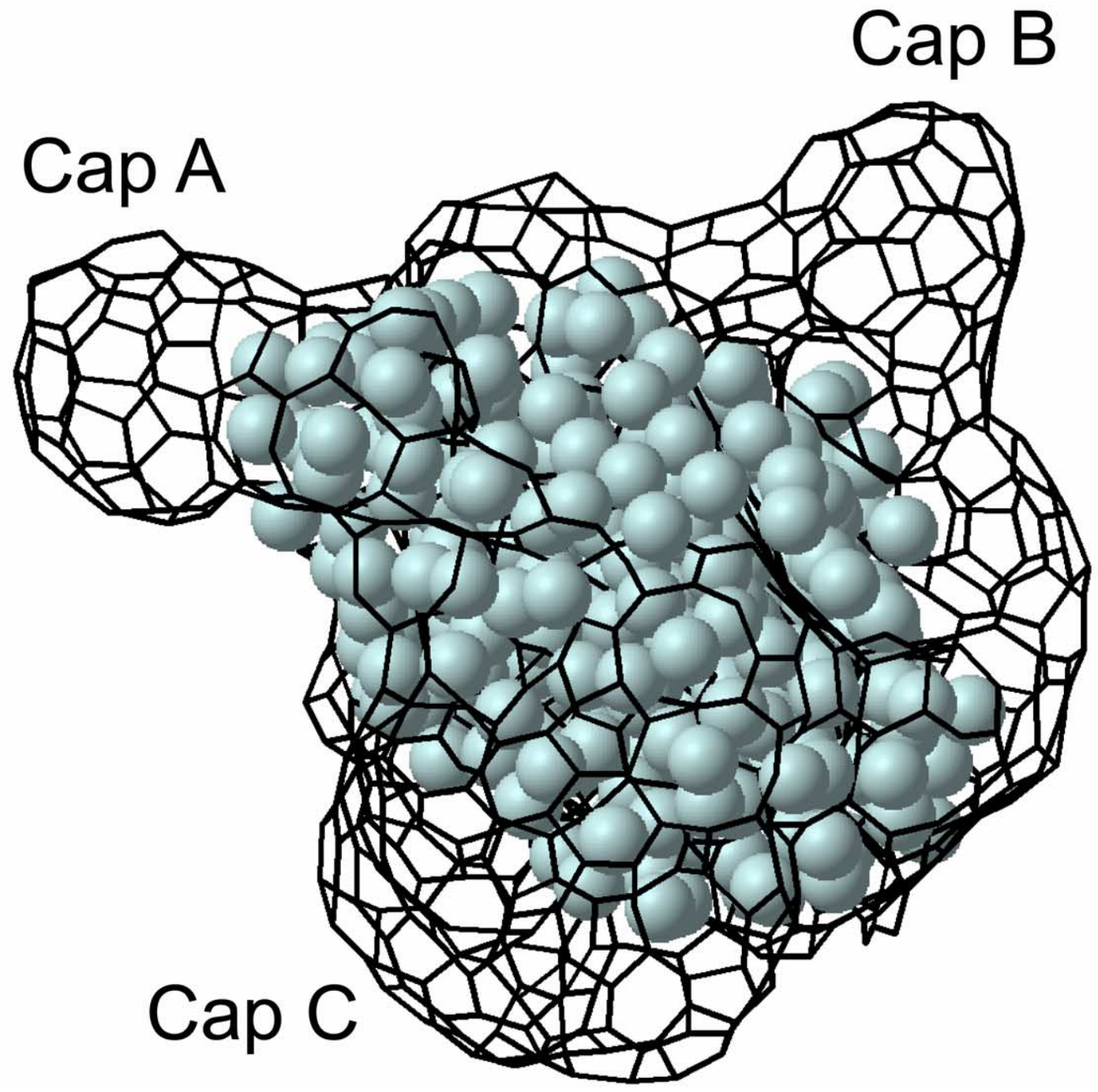

Fig. 5 